\title{
LOS ARTESANOS DE LA ENSEÑANZA POS-MODERNA. HACIA EL ESBOZO DE UNA PROPUESTA PARA SU FORMACIÓN ${ }^{1}$
}

\author{
Artisans of post-modern teaching. \\ Outlining a proposal for their formation
}

\author{
Andrea Alliaud* \\ Fecha de recepción: 20/07/2014 • Fecha de aceptación: 03/11/2014
}

Resumen. La matriz originaria de la profesión asociada a los orígenes de la escuela moderna da cuenta de los rasgos constitutivos de la formación docente, algunos de los cuales se han ido superando mientras que otros se mantienen. Es frecuente que tanto los modelos como las prácticas de formación disocien la teoría y la práctica, el pensamiento de la acción. Aún en los currículos más actualizados de la región, los espacios destinados a la transmisión del conocimiento formalizado se fueron complejizando, mientras la "práctica» ha mantenido la concepción originaria que la identifica con el hacer, es decir, con la «aplicación» del saber aprendido en otras instancias.

Sostenemos en este artículo que las dificultades o imposibilidades detectadas a la hora de enseñar en el presente se deben, fundamentalmente, a que maestros y profesores no han aprendido el oficio. Intentamos esbozar una propuesta formativa poniendo en valor los saberes de la experiencia, y avanzamos hacia modos de formar superadores de la dicotomía clásica entre teoría-práctica, saber-hacer, pensamiento y acción. Rasgos tales como la modelización y la vocación devenida en compromiso son recuperados y re-significados para la formación de docentes que sepan enseñar en los escenarios educativos actuales.

Palabras clave: Oficio docente. Formación docente. Saberes. Prácticas. Planes de estudio.

\footnotetext{
* Departamento de Ciencias de la Educación. Facultad de Filosofía y Letras. Universidad de Buenos Aires. El Salvador 5083. Ciudad Autónoma de Buenos Aires. CP. 1414. Argentina. andrealliaud@ ciudad.com.ar
}

\footnotetext{
${ }^{1}$ El titulo de este artículo parafrasea a una clásica obra escrita por la educadora socialista y defensora de los derechos humanos, Delia Etcheverry, denominada Los artesanos de la enseñanza moderna, editada en 1958 en Buenos Aires por la Editorial Narcea.
}

Cómo citar este artículo: Aillaud, Andrea, «Los artesanos de la enseñanza pos-moderna. Hacia el esbozo de una propuesta para su formación», Historia y Memoria de la Educación, 1 (2015): 319-349. 
Abstract. The origins of the teaching profession together with the genesis of the modern school provide us with the defining features of teachers' education. Some of these features have evolved while others have remained intact. It is quite common for the teacher-training models and training practices to suffer from a disassociation of theory and practice, of thought and action. Even in the most updated curricula of the region, the realm destined to the transmission of formalized knowledge has become increasingly complex, while the "practice» has tended to adhere more closely to its original conception, which identified it with «doing», i.e., with applying the knowledge acquired elsewhere.

In this article we hold that difficulties or obstacles detected in current teaching are due fundamentally to the fact that teachers and professors have not truly learned their craft. We outline an approach to training that places value on knowledge gained from experience, and we propose training methods that help overcome the classical dichotomy between theory and practice, knowledge and application, thought and action. We also bring back approaches such as modelling and vocation-as-commitment, providing teachers with new understandings that will better enable them to carry out their profession in today's educational scenarios.

Key Words: Teaching craft. Teacher education. Knowledge. Practices. Curricula.

\section{INTRODUCCIÓN}

Si bien enseñar nunca fue tarea sencilla, en la actualidad se complica. Los cambios sociales, culturales, los avances tecnológicos han impactado en las instituciones y en los vínculos que en su interior se generan. La escuela moderna como «maquinaria de imposición de identidades» se encuentra debilitada y cuestionada. El oficio de enseñar concebido como un «trabajo sobre otros ${ }^{2}$ destinado a la formación/transformación de las personas, si bien subsiste, se encuentra actualmente afectado. Así y todo, el sistema educativo que ha dejado atrás su exclusividad, que halla resentida su legitimidad y cuyos agentes ya no se hallan motivados de la misma manera, funciona. Hasta el momento, siguen siendo las escuelas las instituciones que posibilitan el pasaje de un acervo cultural "común» entre las generaciones de manera sistemática, pautada y masiva, así como la formación de ciudadanía.

\footnotetext{
${ }^{2}$ François Dubet, El declive de la institución. Profesiones, sujetos e individuos en la modernidad (Barcelona: Gedisa, 2006).
} 
El oficio de enseñar como oficio moderno ha «mutado». Para enseñar hoy, maestros y profesores tienen que crear condiciones que no están dadas o aseguradas, más allá de lo que acontece. Paradójicamente, en tiempos de declive y decadencia de los procesos de socialización e intervención sobre las personas, se le pide mucho a las escuelas y a sus maestros: desde lo más elemental hasta lo más complejo. Ya no alcanza con que enseñen a leer, escribir, realizar operaciones matemáticas básicas y tener una noción general sobre la historia y geografía locales; hoy la escuela tiene que asegurar la apropiación de conocimientos y habilidades complejas, necesarias para convivir y relacionarse con otros. Y este mandato ya no es exclusivo para algunos sino que se pretende alcance a todos y todas. De manera más o menos directa, la escuela está llamada no sólo a afrontar sino a resolver o, al menos, a apaciguar los problemas derivados de la injusticia social. Semejantes demandas recaen sobre una institución que, además, conserva casi intactos la mayoría de sus rasgos originarios: una determinada distribución espacio-temporal, el conocimiento dividido por asignaturas, el agrupamiento de los alumnos por edades, ciertos rituales, la relación (escolar) con el conocimiento, los sistemas de promoción, etc.

En este marco de transformaciones que atraviesan los sistemas educativos y la docencia, se hace necesario revisar cuáles son los saberes y procedimientos necesarios para formar docentes para la escuela de hoy. Si bien las instancias de preparación profesional han atravesado transformaciones profundas, sobre todo a partir de las últimas décadas, aún parece quedar pendiente el desafío de formar docentes que puedan y sepan enseñar en los escenarios educativos de la actualidad.

Basándonos en el saber acumulado, producto de una serie de investigaciones destinadas al estudio del "saber de la experiencia» ${ }^{3}$-aquel que los docentes producen en su actividad cotidiana-, este trabajo pretende transitar por un camino alternativo. En una primera parte, nos detendremos a analizar las características de la matriz fundacional de la docencia, asociada al surgimiento y expansión de la escuela moderna para tomar como referen-

\footnotetext{
${ }^{3}$ Se trata de «El saber de la experiencia. Experiencias pedagógicas, narración y subjetividad en la trayectoria profesional de los docentes», subsidio UBACYT 2004-2007; «Pedagogos, docentes y relatos de experiencia. Saberes pedagógicos y experiencias formativas producidas en la trayectoria profesional». Subsidio UBACYT 2008-2010; y «Dimensiones del saber profesional docente. Su estudio y aportes a la formación». Subsidio UBACYT 2011-2014. IICE, Facultad de Filosofía y Letras, UBA. Directora: Dra. Andrea Alliaud.
} 
cia aquello que cambia y también lo que permanece, así como lo que merece ser recuperado o re-significado por ser constitutivo de un trabajo que se ejerce sobre las personas. Seguidamente, presentaremos las tendencias más actuales de las propuestas de formación vigentes en la región, en las que se visualiza un acrecentamiento y nivel de complejidad de los saberes formalizados, mientras continúan siendo las prácticas los ámbitos «naturales» para aprender el oficio de enseñar. Tensionados estos modelos de formación con la percepción de maestros y profesores que consideran que les cuesta enseñar o no pueden hacerlo, resaltamos la importancia de transmitir a lo largo de todo el proceso formativo los "saberes de oficio", siempre necesarios pero hoy imprescindibles para saber y poder hacerlo. El tránsito por los antiguos gremios y talleres de los artesanos tanto como por los centros donde se forma a los adultos en un oficio, nos dio pistas para avanzar en el esbozo de una propuesta formativa que integra las dimensiones del saber y el hacer, la teoría y la práctica, el pensamiento y la acción, así como en las estrategias formativas que de ella derivan. El camino queda abierto para continuarlo y enriquecerlo con otras creaciones.

\section{LA DOCENCIA EN SUS ORÍGENES}

En Argentina, como en la mayoría de países de América Latina, la docencia surge bajo el amparo estatal. Efectivamente, entre la segunda mitad del siglo XIX y las primeras décadas del siglo XX, fue el Estado Nacional el encargado de crear instituciones especializadas y de regular tanto la formación como el puesto laboral docente. La Escuela Normal es la institución que se consolida y expande con la finalidad de formar maestros «capaces de dirigir con éxito las escuelas que se les confíe y de dar impulso vigoroso al desarrollo de la educación común». ${ }^{4}$ De este modo, el proceso por el cual surge y se desarrolla una formación especializada para los maestros está asociado al surgimiento y expansión de los sistemas educativos nacionales que cobra sentido, a su vez, en el marco de un proyecto de unificación nacional y de integración económica al capitalismo mundial. ${ }^{5}$

\footnotetext{
${ }^{4}$ Decreto Ministerial Roca-Wilde, Memorias presentadas a las Cámaras (Ministerio de Justicia, Culto e Instrucción Pública (MJCIP), 1885), 471.

${ }^{5}$ La formación de profesores para el nivel medio (nivel preparatorio para la universidad) atravesó otro circuito formativo que incluyó a las universidades nacionales y posteriormente a Institutos que ofrecían titulaciones pedagógicas a quienes contaban con formación profesional, hasta que paulatinamente fueron aceptando a egresados de los bachilleratos.
} 
La obligatoriedad de la escolaridad básica, y como corolario de ello, la gratuidad y la laicidad, expresados en la primera Ley de Educación Nacional, ${ }^{6}$ fueron los puntos clave de una política educativa que llegó a concebir a la escuela como pilar de la República y sustento del progreso. En este marco, la acción permanente del Estado se destinó a montar un aparato escolar, con escuelas diseminadas por todo el territorio nacional, que aseguraba continuidad y homogeneidad en los modos de inculcación, en términos de «una tecnología replicable y masiva para culturizar a grandes masas de población [...] para dominar y encauzar la conducta infantil». ${ }^{7}$ Tanto la preparación como el reclutamiento y la carrera de los «agentes legítimos» para garantizarlo fueron asimismo parte de este montaje que pretendió monopolizar los procesos de transmisión de la «cultura legítima» a los fines de alcanzar la unificación social:

La escuela está llamada a resolver un serio problema de dinámica moral y mental [...]. Los hijos reflejan las idiosincrasias sociales o de raza de sus padres y la escuela debe inculcarles alma nueva. ${ }^{8}$

La actuación sobre los otros, propia del oficio de enseñar, se presenta exacerbada en el «programa institucional de la modernidad» que como modo de socialización presenta condiciones lo suficientemente estables como para transformarlos radicalmente. Los procesos de socialización, así entendidos, suponen la interiorización de valores y principios universales mediante un trabajo profesional específico y organizado. ${ }^{9}$ En este contexto, la tarea del maestro consistió en regenerar, transformar a las mayorías «incultas» en «ciudadanos» que en posesión de ciertos hábitos, normas, pautas de comportamiento y saberes básicos pudieran respetar e integrarse al orden establecido ${ }^{10}$ :

\footnotetext{
${ }^{6}$ Ley No 1420 de Educación Común, sancionada el 8 de julio de 1884.

${ }^{7}$ Pablo Pineau, Inés Dussel y Marcelo Caruso, La escuela como máquina de educar (Buenos Aires: Paidós, 2001), 22.

${ }^{8}$ Informe de Dirección de la Escuela Normal de Concepción del Uruguay, Memorias presentadas a las Cámaras (MJCIP, 1898), 388.

${ }^{9}$ François Dubet, El declive de la institución.

${ }^{10}$ En gobiernos oligárquicos, tal como era el de nuestro país durante el proceso de unificación nacional y creación de la nacionalidad por parte del Estado (1880-1912), el respeto y la admiración hacia el orden establecido tanto como la integración al mismo, primaron sobre la participación política. De todos modos, si la escuela puede considerarse principalmente como una "máquina de imposición de identidades», también extendía un pasaporte a mejores condiciones de existencia. Ver Beatriz Sarlo, «Cabezas rapadas y cintas argentinas», en La máquina cultural (Buenos Aires: Ariel, 1998), 67.
} 
aprovechad cada uno de los instantes de la vida escolar para afianzar en el niño sentimientos de admiración y reconocimiento para con Dios, de amor y abnegación para la patria, de respetuoso cariño para con sus padres y maestros y de benevolencia para sus semejantes. ${ }^{11}$

Desde esta perspectiva, socializar/civilizar a un pueblo compuesto en su mayoría por nativos e inmigrantes implicaba educarlo antes que instruirlo. El famoso lema de la época: «combatir la ignorancia», tuvo más que ver con «formar el corazón de la niñez, sugerirle ideas nobles e inspirarles hábitos de orden y trabajo" ${ }^{12}$ que con el acceso a los conocimientos y a la cultura dominante, a los que sólo accedía una minoría. Desde la óptica de las clases dirigentes, la instrucción en sí misma era considerada perjudicial en la medida que «servirá a la juventud de instrumento para el desborde de sus pasiones, dándonos delincuentes refinados». ${ }^{13}$

Así entendida, la acción escolar implicaba más que nada enseñanza y dirección en un sentido "disciplinador» que no sólo corrige o endereza, sino también encauza o promueve buenas costumbres y maneras propias de un «sujeto educado». Los maestros de educación básica, en tanto pilares fundamentales de este proceso de «regeneración social», tenían que encarnar en su persona todos aquellos atributos que se pretendía fueran patrimonio de los destinatarios de su accionar. El maestro ejemplar debía ser portador de hábitos, modales, maneras y cualidades «morales», tanto dentro como fuera de la escuela. Amparados por la fuerza simbólica del poder estatal, su tarea «modeladora» se exalta, se magnifica, llegando a adoptar el carácter sacro que le dio origen al oficio, aún en pleno auge del positivismo y la laicidad:

Repárese que la sacralización y exaltación del maestro no le viene dada por ser docente, por enseñar en sentido estricto [...]. Maestro no es, como fue el leccionista, o son el instructor y el enseñante,

\footnotetext{
${ }^{11}$ Informe de Dirección de la Escuela Normal de Gualeguaychú, Memorias presentadas a las Cámaras (MJCIP, 1892), 539.

12 Conferencia doctrinal, pronunciada en la Asamblea Extraordinaria de Inspectores, Técnicos, Directores y Preceptores de las Escuelas de la Capital, 1898. Maestros de la Capital (Buenos Aires: Imprenta Castex y Halliburton, 1898), 510.

${ }_{13}$ Conferencia doctrinal, pronunciada en la Asamblea Extraordinaria de Inspectores, Técnicos, Directores y Preceptores de las Escuelas de la Capital, 1898. Maestros de la Capital (Buenos Aires: Imprenta Castex y Halliburton, 1898), 511.
} 
quien instruye o quien enseña, sino quien tiene la fuerza de imponerse como modelo ante otro. No es el ejercicio técnico lo que se sacraliza, sino la relación de dominación. ${ }^{14}$

Se comprende así que el atributo «normal» de las instituciones formadoras de docentes remita tanto a la norma, al método de enseñanza, que a partir del surgimiento de la Pedagogía como «ciencia de la educación» contó con una base científica, como a la normalización/disciplinamiento que asimismo definió la formación de los maestros: «La primera condición para ejercer el magisterio es una conducta intachable y una moralidad probada». ${ }^{15}$ Desde esta perspectiva, para ejercer como maestro se requería además de formación especializada, buenas respuestas en las cuestiones referidas al «ser»: rutinas, prácticas y una alta dosis de moralidad. El énfasis puesto en la personalidad de los educadores, favoreció el asiento de una doctrina de salvación que a la vez le sirvió de sustento, aún en el momento en el que se institucionaliza su formación. ${ }^{16}$ La exigencia de la vocación como cualidad natural para ejercer la enseñanza fue prioritaria a la hora de evaluar el ingreso o la preparación del futuro docente: «han tenido ocasión de probar [las graduadas de la escuela normal del Uruguay] dos cosas igualmente satisfactorias, que tienen idoneidad para mentoras de la infancia, y vocación para consagrarse al magisterio». ${ }^{17}$

Los primeros planes nacionales de formación docente para las Escuelas Normales que datan de 1887 presentan un listado de materias con su respectiva carga horaria distribuidas a los largo de los tres años de duración, si eran para Maestras, o cinco para el caso de los profesores, «en una progresión metódica y según un desarrollo lógico» que comprendía los contenidos de las distintas disciplinas y Pedagogía. Entre los considerandos de esta norma nacional se menciona al «personal docente, como parte primordial de la instrucción pública», aunque se considera

${ }^{14}$ Carlos Lerena, «El oficio de maestro. Posición y papel del profesorado de primera enseñanza en España», en Educación y Sociología en España, ed. Carlos Lerena (Madrid: Akal, 1987), 444. Subrayado de la autora.

${ }^{15}$ Informe de Dirección de la Escuela Normal de Catamarca, en Memorias presentadas a las Cámaras (MJCIP, 1899), 301.

${ }^{16}$ Andrea Alliaud, Los maestros y su historia: los orígenes del magisterio argentino (Buenos Aires: Granica, 2007, $2^{\text {a }}$ edición).

${ }^{17}$ Informe de Dirección de la Escuela Normal de Concepción del Uruguay, en Memorias presentadas a las Cámaras (MJCIP, 1886), 388. 
imprescindible limitar racionalmente el número de las asignaturas para conseguir por este medio que (los maestros) adquieran la debida competencia profesional y conozcan ampliamente las materias que a su vez han de enseñar, sin recargo perjudicial de trabajo y con prescindencia de ciertos ramos que no corresponden a la Escuela Normal.

Anexa a cada Escuela Normal funcionará, con el nombre de Escuela de Aplicación, una escuela primaria completa, que servirá de modelo a los aspirantes al magisterio, y en la que estos se ejercitarán practicando los sistemas y métodos pedagógicos y aplicando las reglas fundamentales del arte de enseñar. ${ }^{18}$

En esta primera etapa para ingresar a la formación docente se exigía haber aprobado el nivel primario aunque la titulación docente no permitía el ingreso a las universidades, lo cual aconteció recién en 1942 cuando a los tres años del ciclo básico del nivel medio se agregan dos más de formación especializada. En la década de los setenta del pasado siglo, la formación docente pasa al nivel de enseñanza superior y exige dos años de estudio posteriores al nivel secundario y medio año más destinado a la Residencia. ${ }^{19}$

Las prescripciones formativas originarias reflejan: la necesidad de acotar la formación de los docentes a un conjunto de conocimientos básicos, acorde con las características propias del puesto de trabajo; la impronta modelizadora y vocacional del proyecto educativo/formativo, acorde con la función moralizadora de la escuela y la labor educadora de sus docentes, y también la concepción de la enseñanza entendida como "aplicación» de aquello que se aprendió en las instancias de formación profesional. Desde esta visión, los docentes tienen que estar formados para «hacer», es decir, para poner en acto un conjunto de saberes producidos y definidos por otros. Pareciera ser que tanto el «ser» como el «hacer» desplazan al saber en la formación de los educadores. Más que la apropiación del contenido científico, el discurso pedagógico moderno valora su asimilación: «Formando maestros que posean menos ciencia, pero mejor digerida, tal vez será posible acercarnos a llenar las necesidades de la instrucción primaria». ${ }^{20}$

\footnotetext{
${ }_{18}$ Plan de Estudios de las Escuelas Normales, diciembre de 1887, Departamento de Instrucción Pública.

${ }^{19}$ En Argentina se denomina «Residencia» al período de formación profesional en prácticas de enseñanza que, en estos planes de estudio, acontecía en el último tramo de la carrera. Durante el mismo, los/as futuros/as docentes llevan adelante intervenciones pedagógicas prolongadas en contexto de clases «reales».

${ }^{20}$ Informe de Dirección de la Escuela Normal de Mendoza, en Memorias presentadas a las Cámaras (MJCIP, 1885), 322.
} 
Como se verá en lo que sigue del trabajo, estas improntas fundacionales constituyen fuertes configuraciones de pensamiento y acción cuyos vestigios llegan hasta el presente, aún cuando los escenarios sociales y educativos sean muy diferentes a los de la época del surgimiento del sistema educativo nacional y, absolutamente ligado a ello, a los orígenes de la profesión docente.

La tradición normalizadora-disciplinadora (de los alumnos y de los docentes) sigue presente en la actualidad, tanto en los estilos objetivados de formación inicial como en el desarrollo de los puestos de trabajo y en las imágenes sociales circulantes [...]. Aunque en su origen esta tradición se consolida especialmente en la formación de docentes para la escuela primaria, sus rasgos centrales se extienden a la imagen del «buen docente», con independencia de su actuación en un nivel determinado de enseñanza. ${ }^{21}$

\section{LA FORMACIÓN DOCENTE HOY}

En la actualidad la formación de los docentes en la mayoría de los países de América Latina se lleva a cabo en el nivel superior (institutos superiores y universidades), si bien quedan resabios de docentes formados en el nivel medio que se desempeñan sobre todo en los niveles básico e infantil, como en el caso de Brasil, o docentes que no cuentan con formación pedagógica, tal como sucede en Paraguay. ${ }^{22}$

Desde finales de los años 80 , se observa en la región una tendencia a la prolongación de los estudios y un aumento en las horas destinadas a la formación: la duración de las carreras que forman docentes en los países del MERCOSUR ${ }^{23}$ oscila entre 3 y 4 años de duración y 3000 horas en promedio. La tendencia señalada se evidencia al considerar que, por ejemplo, en Argentina en los años 70 —durante el mismo siglo— las carreras docentes

${ }^{21}$ Cristina Davini, «Tradiciones en la formación de los docentes y sus presencias actuales», en La formación docente en cuestión: política y pedagogía (Buenos Aires: Paidós, 1995), 26.

${ }^{22}$ Las apreciaciones referidas a la región se desprenden de un estudio llevado a cabo en el marco del Programa de Apoyo al Sector Educativo del Mercosur (PASEM), cuyo propósito fue comparar los planes de formación docente inicial, así como la oferta y organización de la formación continua existente en los países miembros fundadores (Argentina, Brasil, Paraguay, Uruguay). Ver PASEM (coord., Andrea Alliaud), Los sistemas de formación docente en el MERCOSUR. Planes de estudio y propuestas de formación continua (Buenos Aires: PASEM/OEI/TESEO, 2013).

${ }^{23}$ El MERCOSUR es una asociación entre los países mencionados que persigue fines comerciales, políticos, educativos y culturales. 
tenían una duración de dos años en el nivel superior y una carga horaria de 600 horas.

Tratando de dar respuesta a los desafíos de época y en sintonía con la importancia otorgada por las políticas educativas a la docencia para la mejora de los sistemas educativos, los planes de formación docente no sólo se han extendido sino también se han complejizado. Al analizar los perfiles docentes que las propuestas curriculares vigentes en la región expresan, se nota que las capacidades/habilidades/competencias requeridas trascienden a un saber acotado a los fines de su utilización. Si bien la preocupación por la enseñanza cobra protagonismo, se espera de los docentes: la reflexión y comprensión de las dimensiones socio-políticas, histórico-culturales, pedagógicas, metodológicas y disciplinarias (de las disciplinas de estudio); la dimensión ética de la profesión, la contemplación de los contextos sociales y las problemáticas contemporáneas; el compromiso con los valores democráticos; el dominio de los contenidos y de su significado en diferentes escenarios y su articulación interdisciplinar); el conocimiento de los procesos de investigación, el desarrollo profesional y la formación permanente. ${ }^{24}$

Dadas estas exigencias, los planes de formación docente se han diversificado en un número creciente de espacios curriculares que comprenden, además de los contenidos disciplinares y las maneras de enseñar que maestros y profesores deben «dominar» según la especialidad y/o nivel educativo para el que se están formando, otros referidos a la problemática de los sujetos (en sus distintas dimensiones psicológicas, sociales, culturales), de los contextos, de las instituciones, de la contemporaneidad, así como nuevas destrezas tales como la reflexión, la indagación, la investigación. Ya no se trata de focalizar sólo en las disciplinas y su enseñanza, sino de incorporar a la formación docente las problemáticas propias de los nuevos escenarios sociales y culturales, las subjetividades de quienes aprenden, las nuevas tecnologías de la información y la comunicación, etc. Desde estos planteamientos habría que, principalmente, «jerarquizar» la tarea docente, ofreciendo las posibilidades y oportunidades para que quienes enseñan se apropien de ciertos códigos culturales, de ciertos marcos conceptuales que les permitan estar mejor posicionados a la hora de tomar las decisiones más específicas acerca de lo que tienen que hacer con los alumnos. ¿Será que la apropiación de nuevos marcos conceptuales y cultura-

${ }^{24}$ Son sólo algunos de los rasgos comunes que presentan los perfiles docentes de los planes de formación inicial de los países estudiados (PASEM, Los sistemas de formación docente en el MERCOSUR, 36-38). 
les resulta suficiente para asegurar que maestros y profesores puedan enseñar en el presente? Pareciera que no, de allí la recurrencia en los planes de estudio a intensificar los aportes de las didácticas específicas. Sin embargo, pareciera que tampoco es suficiente y las modificaciones alcanzan los espacios formativos destinados a la práctica profesional. ${ }^{25}$

La intensificación de la formación práctica fue asimismo una transformación sustancial que atraviesa a los nuevos planes de formación docente. Los espacios curriculares destinados a las prácticas han cobrado protagonismo y esta tendencia se visualiza tanto en la región como en los países de la Unión Europea. No sólo se ha aumentado la carga horaria, sino que se le otorgó a este campo de la formación un tratamiento diferencial. Los «modelos concurrentes» han superado a los consecutivos que la colocaban al final de los planes de estudio: se trata en el presente que las prácticas profesionales se incorporen desde los inicios de la formación y contemplen las distintas dimensiones del quehacer profesional. Asimismo, su tratamiento situado y contextualizado apunta a formar docentes que puedan desempeñarse en contextos y escenarios educativos reales. Si bien en muchos planes se expresa la necesidad de articular los espacios de la práctica con los otros campos o espacios de la formación (Paraguay: «confrontar de manera sistemática su formación teórica con las dificultades concretas de las situaciones de enseñanza, en las diferentes modalidades y contextos educativos»), o se destaca la importancia de lograr la articulación de los conocimientos prácticos y de los brindados por los otros campos curriculares (Argentina), asociar las instancias de formación teórica con los espacios de la práctica ha sido y sigue siendo un problema difícil de superar en la formación docente: las prácticas profesionales suelen concebirse como espacios destinados al «hacer» o "poner en práctica» lo aprendido, mientras que los otros espacios curriculares de la formación —al estructurarse casi exclusivamente a partir de conocimientos formalizados - se conciben como espacios destinados al «saber» en el sentido de conocer lo que luego tendrá que «aplicarse». ${ }^{26}$

Al respecto parece novedosa y superadora de esta problemática una propuesta pedagógica de Brasil $^{27}$, que admite la práctica como un compo-

\footnotetext{
25 PASEM, Los sistemas de formación docente en el MERCOSUR, 26.

26 PASEM, Los sistemas de formación docente en el MERCOSUR, 40-42.

27 Se trata de la Universidad Federal de San Pablo (Unifesp) y las carreras son Pedagogía (que forma docentes para educación infantil y primaria), Ciencias Biológicas y Matemática.
} 
nente curricular de los distintos espacios formativos: todas las unidades curriculares de la formación general deben tener su dimensión práctica, con la finalidad de promover la articulación de las diferentes prácticas en una perspectiva interdisciplinar. Antes que presentarse como un campo aislado que luego hay que articular con el resto, en el diseño brasilero las prácticas profesionales atraviesan la totalidad del currículum. En los planes de profesorado de Uruguay, las prácticas forman parte de las Didácticas específicas pero no atraviesan la totalidad del plan, como en el caso de Brasil.

Nada de esto es desdeñable. En algún caso, estas propuestas formativas y las prácticas que de ellas derivan resultaron necesarias para lograr que maestros y profesores aprendan a enseñar; sin embargo, la mayoría de las veces demostraron sus limitaciones. Por más capacitación, actualización o perfeccionamiento que reciban, los docentes parecen resistentes ( $i$ impermeables?) a la hora de plasmar en las aulas lo que aprendieron» en los espacios de formación. Así, lo que prima en las situaciones de enseñanza suele ser lo que sabían, producto de lo que alguna vez aprendieron de su propia biografía escolar, lo que les resulta o resultó a lo largo de su trayectoria laboral o simplemente lo que les «sale» como mezcla de todo ello. No obstante, el problema fundamental aparece ante la complejidad que la enseñanza adquiere en la actualidad, cuando ya no resulta suficiente apelar a lo que se vivió en la propia escolaridad (las escenas vividas cuando uno fue alumno poco tiene que ver con lo que pasa en las aulas de hoy), ni parece posible afrontar el proceso que demanda ir aprendiendo el oficio en el puesto laboral (las escenas presentes se imponen). Ya no se trata de ser más o menos tradicionales, conservadores o reproductores: frecuentemente los docentes de hoy protagonizan situaciones escolares en las que perciben que no pueden enseñar y reclaman que no están preparados, a pesar de haber transitado por numerosos ámbitos de formación sistemática. Así se expresaba una docente argentina, Marisa Waimann, en un debate público: «Nunca antes tuve tantos recursos, nunca hice tantos cursos de capacitación y, sin embargo, nunca tuve tantas dificultades para enseñar». ${ }^{28}$

La fuerte institucionalización que por muchos años sostuvo los procesos de intervención sobre las personas, empezó a debilitarse hace ya más

28 «Docentes en crisis. El desafío de estar frente a un aula y no saber cómo enseñar», La Nación, 24 de febrero de 2013 (debate público). Disponible en_http://www.lanacion.com.ar/1557468-docentes-en-crisisel-desafio-de-estar-frente-a-un-aula-y-no-saber-como-enseñar. 
de medio siglo, acelerándose en las últimas décadas. El «programa institucional» de la modernidad se halla debilitado, «resquebrajado», lo cual no implica que no funcione ${ }^{29}$, sino que ha adquirido una nueva fisonomía que a veces nos puede complicar pero que no podemos negar pensando, por ejemplo, que "ya va a pasar». La pluralidad de los valores, el espíritu crítico, el derecho de los individuos a determinarse, la proliferación de instancias de circulación del saber y la información, el crecimiento del nivel de escolaridad promedio de la población, las nuevas configuraciones familiares, son cambios que progresivamente vinieron a imponerse, poniendo en cuestión el poder de las grandes maquinarias para fabricar subjetividades y regular las prácticas de los individuos. ${ }^{30}$ De este modo, lo que antes estaba asegurado institucionalmente ahora tiene que ser garantizado por los sujetos en su labor cotidiana. Intervenir sobre las personas hoy (enseñar, educar, hoy) es menos el cumplimiento de un rol que la construcción de una experiencia, afirma Dubet. ${ }^{31}$ Hasta no hace tanto, por el sólo hecho de ocupar «el lugar de» (maestro o profesor) se era reconocido, respetado, escuchado, admirado... y podríamos continuar. Actualmente, para poder enseñar, maestros y profesores tienen que poder construir (con los otros) condiciones que ya no están dadas automáticamente ni legitimadas trascendentalmente: «Cuando yo enseñaba, lo que decía el maestro era sagrado», recuerda Marta Ochoa, que hoy cumple 82 años y fue maestra durante dos décadas y media, en el siglo pasado. ${ }^{32}$

Vale resaltar que no le quitamos importancia ni a la intensificación de los contenidos ni al incremento y gradualidad de la formación práctica. Pretendemos contar con docentes conocedores, renovados y críticos, analíticos pero ante todo nos preocupa que los maestros y profesores puedan enseñar en estas nuevas condiciones o, mejor, aspiramos — quizás corriendo el riesgo de parecer demasiado utópicos- a que quienes lograron llegar a las escuelas (muchos de los cuales quedaron excluidos por muchos años)

\footnotetext{
29 Dubet, El declive de la institución, 420.

30 Según Dubet (El declive de la institución, 421-422) el programa institucional de la modernidad llevaba inscripta esta contradicción al pretender conjuntamente la socialización de los individuos y su liberación. Desde esta perspectiva, la extensión de los niveles de escolarización conduce, a la larga, a procesos de mayor autonomía.

31 Dubet, El declive de la institución, 21.

32 «Docentes en crisis. El desafío de estar frente a un aula y no saber cómo enseñar», La Nación, 24 de febrero de 2013 (debate público). Disponible en http://www.lanacion.com.ar/1557468-docentes-en-crisisel-desafio-de-estar-frente-a-un-aula-y-no-saber-como-enseñar.
} 
aprendan. Por más que actualicemos y complejicemos los contenidos, la formación entendida como información resultará "resbaladiza» para docentes experimentados, formados y «formateados» por su propia experiencia escolar o laboral y desafiados por puestos laborales en los que permanentemente tienen que ir creando y re-creando las condiciones de su accionar, justificando y negociando sus decisiones. Asimismo, la intensificación de la formación práctica pierde sentido mientras siga prevaleciendo la concepción aplicacionista originaria que la identifica como la «bajada» de lo aprendido en los espacios de formación al aula. Hoy, dada la transmutación que han atravesado las instituciones y las formas de transmisión cultural entre las generaciones, resulta necesario que maestros y profesores estén preparados para probar, experimentar, crear, innovar. Enseñar hoy, es menos que nunca «aplicar» o «bajar» lo aprendido en el profesorado o en algún espacio de capacitación al aula, como tampoco de lo que hemos planificado. Enseñar hoy es aprender a permanecer en la confusión, en la imprevisibilidad, es tener que decidir en contextos de cambio. En estos escenarios tanto los saberes disponibles como lo que pueda anticiparse, constituyen referencias que siempre estarán sujetas a lo que no sabemos que a va a ocurrir y efectivamente ocurre.

\section{HACIA EL ESBOZO DE UNA PROPUESTA DE FORMACIÓN BASADA EN LA EXPERIENCIA}

Sostendremos en este escrito que las dificultades o imposibilidades detectadas a la hora de enseñar se deben, fundamentalmente, a que maestros $y$ profesores no han aprendido el oficio. Y no es, en muchos casos, porque no sepan los conocimientos formalizados (disciplinares o pedagógicos), lo que no saben es «obrar» a partir de ellos, con ellos. Al concebir la enseñanza como oficio, es posible afirmar que lo que falla es la posibilidad de intervenir, de provocar cambios en los otros, de «producir» sujetos transformados en algo distinto a lo que eran. ${ }^{33}$ Además de las consecuencias que esta imposibilidad genera, en términos de aprendizajes de los alumnos, el hecho de no ver plasmado su procedimiento o intervención en "obra», es lo que quita el sentido a la tarea y lo que deja a los docentes desprotegidos ante sí mismos y ante la sociedad en general: las crisis de identidad, de autoridad, tan comunes en esta época, tienen mucho que ver con ello.

33 Dubet, El declive de la institución, 17. 
En escenarios escolares de alta complejidad e incertidumbre como son los del presente, es del todo frecuente que los maestros y profesores no puedan enseñar o les cueste, porque nadie se ha ocupado de trasmitirles ese saber específico, esos «saberes de oficio» que les permiten «saberhacer» (todo junto) o saber obrar que, sabemos hoy, se aprende mediante formas de transmisión también específicas que no es practicar sin más, ni más práctica. La sumatoria de conocimientos formalizados, por más sofisticados que éstos sean, y la práctica como ámbito de actuación per se, parecen no resultar suficientes para formar docentes que puedan decidir qué hacer y cómo hacerlo. La lógica de la adición y la aplicación aún vigente en los ámbitos de formación docente, parece ya no resultar para aprender a enseñar hoy cuando ni siquiera resuelve apelar a la experiencia acumulada para sortear esta situación. Pero entonces: ¿cómo se enseña a enseñar? ¿Cómo se transmiten esos «otros» saberes tan necesarios para el oficio?

Desde la perspectiva que hemos adoptado, luego de compartir varias horas de trabajo con docentes y formadores y de haber investigado sobre estas cuestiones, ${ }^{34}$ re-afirmamos la importancia de ir construyendo el oficio de enseñar a lo largo de todo el proceso formativo convocando el saber que se produce al enseñar, invitando a la experiencia, creando y re-creando formas o maneras de formar que superen la dicotomía entre la teoría y la práctica, entre el saber y el hacer, entre el pensamiento y la acción, cualidad fundamental para llegar a ser «artesanos». Richard Sennett caracteriza de este modo al saber hacer del «virtuoso»: es mucho más que aplicar una técnica o un conocimiento especializado; no es sólo poder solucionar problemas, es también descubrir nuevos territorios, revisar los supuestos que sostienen nuestras acciones y decisiones. Es comprometerse con lo que se hace, y, fundamentalmente, ser capaz de conjugar el pensamiento con la acción: «Todo buen artesano mantiene un diálogo entre unas prácticas concretas y el pensamiento; este diálogo evoluciona hasta convertirse en hábitos, los que establecen a su vez un ritmo entre la solución y el descubrimiento de problemas». ${ }^{35}$

Si el interés está puesto en formar docentes que sepan y puedan enseñar, en el sentido de intervenir, de accionar con otros y sobre otros, suponiendo que esta habilidad en el obrar produciría buenas obras, buenos productos

\footnotetext{
34 Ver nota $n^{\circ} 3$.

35 Richard Sennett, El artesano (Barcelona: Anagrama, 2009), 21.
} 
(¿buenos resultados?), tendríamos que garantizar maneras de formar no disociadas y dinámicas.

En uno de los movimientos, puede resultar recuperar los saberes que maestros y profesores producen en los procesos de transmisión a lo largo de su trayectoria profesional y también aquellos que provienen de la experiencia acumulada durante su propia escolaridad, por ser éstos necesarios al funcionar como potentes anclas de sostén que les permiten actuar y, potencialmente, pensar, reflexionar sobre lo hecho o actuado a fin de enriquecerlo, mejorarlo. Es mediante la puesta en diálogo de la práctica asimilada y los conocimientos formalizados como se alcanza la "experticia» ${ }^{36}$ y es posible volverse «artesano» o virtuoso en lo que se hace. Retomando a Sennett, las prácticas mejoran $-\mathrm{y}$ pueden mejorar y todos podemos mejorarlas- $\mathrm{y}$ llegan a convertirse en "artesanía» cuando la información y la acción se convierten en conocimiento. ${ }^{37}$ Mediante estos procesos las personas se hacen más habilidosas.

En otro de los movimientos, necesitamos que los saberes formalizados - siempre renovados y actualizados- estén puestos al servicio de producciones, de creaciones, de narraciones, de «obras de enseñanza». En todos los espacios de formación, tenemos que apelar y convocar muchas y variadas experiencias de enseñanza. Experiencias que nos impliquen, que den lugar a un nuevo saber, que nos convoquen a abrirnos a lo que sucede, a pensar, a inventar. Esta perspectiva rompe con la lógica del sistema escolar donde prima lo previsible, lo controlable, lo esperable. Aprender de la experiencia significa estar atento a lo que la práctica muestra, tiene para decir; implica seguir un camino que es creado mientras sigue. Es abrirse a lo que sucede y aceptar lo inesperado. El llamado «saber teórico» puede servir de orientación a la experiencia, pero sin anticipar ni resolver el encuentro ni de lo que de él surgirá, sostienen Contreras y Pérez de Lara, y así lo han expresado:

Es experiencia precisamente porque irrumpe ante lo que era lo previsto, lo sabido; no puede estar sometida a control, ni ser producto

\footnotetext{
${ }^{36}$ En el sentido que le otorga Dewey a la experiencia -El arte como experiencia (México: Fondo de Cultura Económica, 1949), 34- al decir que no es mera actividad sino una fuerza en movimiento que supone cambio y constituye la base del pensamiento reflexivo, investigativo. La práctica, según el autor, se encuentra tanto al comienzo como al final de toda indagación educativa.

${ }^{37}$ La artesanía es entendida por Sennett - El artesano, 20- como la habilidad de hacer las cosas bien, por el simple hecho de hacerlas de esa manera, más allá de los estados subjetivos de sus productores y de finalidades que trasciendan lo que se hace.
} 
de un plan. Por eso obliga a pensar, para ser acogida en su novedad, como lo que no encaja, o lo que necesita de un nuevo lenguaje, una nueva expresión, o un nuevo saber para dar cuenta de ella. Irrumpe también su significado, el sentido de lo vivido. La experiencia lo es en la medida en que reclama significados nuevos para lo vivido. Es experiencia porque nos mueve a la búsqueda de sentido para algo que no lo tenía, o para algo a lo que no se lo habíamos encontrado. Así pues, en ocasiones será la novedad de lo que acontece lo que provoca el sentido de la experiencia, pero en ocasiones será la atribución de un nuevo sentido a lo vivido lo que hará de ello una experiencia. $^{38}$

En un tercer movimiento, se trata de abordar la formación como «experiencia» que habilite a experimentar, a probar y ser puesto a prueba en cada circunstancia. Hacer un buen trabajo significa en esta dinámica tener curiosidad, investigar y aprender de la incertidumbre. Para Dubet, ${ }^{39}$ el oficio autoriza un aprendizaje por tanteo y experimentación. Si acordamos que hacer las cosas bien (enseñar bien o poder hacerlo) exige hoy más que nunca del experimento, la investigación, la exploración, así como la posibilidad de seguir aprendiendo en situación, puede resultar de utilidad reparar en la distinción que Norbert Elías ${ }^{40}$ plantea entre conocimiento y saber: mientras que los conocimientos remiten a un conjunto de significados creados por el hombre, saber es probar. Podríamos decir entonces que quien sabe enseñar es aquel que ha probado muchas y distintas maneras de dar a conocer $\mathrm{u}$ ofrecer al mundo a otros — si aceptamos que tal es la especificidad de este tipo de trabajo que se realiza sobre otros-. Quien conoce, por el contrario, es quien posee un repertorio de conocimientos: quizás sabe qué decir y cómo decirlo, pero no sabe qué hacer. Por lo anterior y nuevamente, los conocimientos formalizados son imprescindibles pero en sí mismos parecen no alcanzar para poder enseñar. Se necesita además «probar» variadas maneras de poner a disposición lo que los otros tienen que aprender y ponerse a prueba en esas circunstancias. Probar varias y diferentes maneras de dar a conocer el mundo. Practicarlas, mansearlas, discutirlas, analizarlas. ${ }^{41}$

\footnotetext{
38 José Contreras y Nuria Pérez de Lara, Investigar la experiencia educativa (Madrid: Morata, 2010), 25.

39 Dubet, El declive de la institución, 205.

${ }^{40}$ Norberto Elías, Conocimiento y poder (Madrid: La Piqueta, 1994), 93-95.

${ }^{41}$ Andrea Alliaud y Estanislao Antelo, «El fracaso de enseñar. Ideas para pensar la enseñanza y la formación en los futuros docentes», en Sentidos perdidos de la experiencia escolar, coord. Daniel Braislovsky (Buenos Aires: Noveduc, 2008), 44.
} 
A esta altura estamos en condiciones de afirmar que son esos «otros» saberes (del trabajo, de la experiencia, de oficio) los que nutren la enseñanza, de allí la relevancia de asegurar desde los ámbitos de formación, tanto inicial como permanente, que los maestros y profesores se nutran de ellos. El desafío de cualquier proceso formativo es formar docentes «experimentados» que puedan «experimentar experiencias»y, así, abrirse a lo que sucede y estar mejor provistos para afrontar lo inesperado sin quedar paralizados. De lo que se trata entonces es de formar docentes que sepan enseñar y no solamente conozcan sobre la enseñanza. Saber es algo que "nos» pasa, no por acumulación de conocimientos sino por la transformación que se produce en nosotros. Es lo que «nos» pasa como producto de lo vivido, de lo vivido hecho experiencia. Si el conocimiento no llega a constituir una experiencia, habrá conocimiento almacenado pero no saber. ${ }^{42}$ En este sentido podemos decir que muchas veces los docentes conocen de qué se trata pero no saben.

Según Larrosa es importante la forma en que se construye y presenta el saber humano si quiere tener efectos en la subjetividad. Parecen facilitarlo los textos o las narraciones que sin pretender universalidad en sus enunciados y siendo fragmentarias voluntariamente, sin pretensión de verdad, pretenden vehiculizar un sentido para lo que nos pasa. Este tipo de textos o las narraciones de experiencias pueden ser interpretados (a diferencia del conocimiento sistemático que sólo puede ser asimilado) desde la situación particular de cada uno. La transmisión de ese «saber de la experiencia», sostiene el autor, tiene que ver con lo que somos, con nuestra formación y nuestra transformación. ${ }^{43}$ El saber que se produce a partir de lo que se experimenta tiene algunas características particulares: es finito y se liga a la maduración de un individuo en particular; es subjetivo, relativo y personal. No está fuera de nosotros, sólo tiene sentido en el modo como configura una vida, un carácter, una sensibilidad. Enseña a vivir humanamente.

El saber de la experiencia, forma y transforma. Enseña. No clausura o encorseta en formas ni formatos establecidos, sino que abre posibilidades. La narración misma es una posibilidad que proviene de sujetos, de situaciones y propicia las creaciones, en tanto expresa un saber que rompe con la lógica de decir o prescribir en quiénes deben convertirse aquellos que se

\footnotetext{
42 Contreras y Pérez de Lara, Investigar la experiencia educativa, 52-54.

${ }^{43}$ Jorge Larrosa, La experiencia de la lectura. Estudios sobre literatura y formación (Barcelona: Laertes, 1998), 27.
} 
están formando. Las prescripciones asociadas a los orígenes de la docencia y la escolaridad moderna son del todo frecuentes y funcionan, de manera implícita y potente, en los ámbitos de formación profesional determinando aquello que los docentes tienen que aprender para llegar a «ser» y a «hacer».

La formación entendida como narración, como relato de experiencias marcadas con la huella del que narra y experimenta o experimentó, podría resultar más convocante, más marcadora, atractiva o impactante. En tanto no explican sino que simplemente cuentan, sin imponerle al posible lector posibles interpretaciones, las narraciones «alcanzan una amplitud de vibración del que carece la información». Estas historias «secas» (libres de explicaciones y contextualizaciones) suelen provocar sorpresa y reflexión ante quienes tienen la posibilidad u oportunidad de compartirlas. ${ }^{44}$

No es sin experiencia, sin sus «cantos» ${ }^{45}$, como se mejorará la formación de los docentes. Desde esta dimensión y tratamiento del saber podrá fortalecerse en el oficio de enseñar a quienes ya enseñan o a quienes van a hacerlo. Frente a posturas que "humillan» o degradan el oficio docente considerando que el «saber especializado», el de los especialistas, es el único válido y legítimo para regular o modificar las prácticas, apostamos por poner en valor y darle un estatuto al saber peculiar de los docentes, de los que son portadores y productores. Y no es una cuestión de valorar o poner en valor porque sí, es una necesidad para poder enseñar en el presente: «fortalecer» el oficio de quienes enseñan o van a enseñar, constituye una opción «alternativa» para la mejora de las prácticas educativas. ${ }^{46}$

\section{FORMAS ESPECÍFICAS PARA LA TRANSMISIÓN DE LOS SABERES DE OFICIO}

Desde los orígenes de la profesión a la actualidad se han podido apreciar las tendencias imperantes en el campo de la formación docente: la prolon-

\footnotetext{
${ }^{44}$ Walter Benjamin, «El narrador», en Para una crítica de la violencia y otros ensayos (Madrid: Taurus, 1999, 2 $2^{\text {a }}$ edición), 117-118.

${ }^{45}$ Parafraseando la obra de Martín Jay, quien considera que «la experiencia puede ser asequible a los demás mediante el relato post facto, un proceso de elaboración secundaria que la convierte en una narrativa dotada de significación» (Cantos de experiencias. Variaciones modernas sobre un tema universal (Buenos Aires: Paidós, 2009), 20).

${ }^{46}$ Andrea Alliaud, «Formación de profesores para la calidad», Revista de Política Educativa, Escuela de Educación. Universidad de San Andrés (UDESA), 4 (2013), 61.
} 
gación de los planes de estudio, por una parte y, por otra, el acrecentamiento de los saberes formalizados junto con el mayor tiempo de dedicación a los espacios de las prácticas profesionales. No obstante, queda en pie avanzar sobre la lógica "aplicacionista» propia de la matriz constitutiva de la profesión. Tradicionalmente, como ya se ha señalado, la práctica docente fue concebida como el lugar propicio para el «hacer». Los conocimientos, las teorías, se aprendían en determinados espacios curriculares y luego en la "práctica» se aplicaba lo que se había aprendido. Antes era al final, hoy es desde el comienzo. Sin embargo, el acrecentamiento y la introducción desde los primeros años de la formación, no implica necesariamente un cambio en su tratamiento. $\mathrm{Y}$ es eso lo que estamos destinados a modificar.

Uno podría objetar que aún bajo estas lógicas antes y a la larga, la enseñanza salía. Y es cierto porque los maestros recién formados solían apelar a su propia biografía escolar e iban acrecentando ese caudal experiencial en el ámbito laboral: aprendiendo por ensayo y error, en soledad y a lo largo de los años, en la medida que enseñaban. La experiencia vivida como alumnos y la que vivían como maestros los formaba o «completaba» su formación. Hoy, dada la complejidad que asumió el oficio, esas formas no son suficientes. No la experiencia, sino la forma de apelar a ella.

¿Y Entonces? Hemos presentado hasta aquí algunos rasgos que permiten ir visualizando una propuesta de formación alternativa que consiste en:

- Ir construyendo el oficio de enseñar a lo largo de todo el proceso formativo.

- Recuperar los saberes que maestros y profesores producen en los procesos de transmisión.

- Apelar y convocar muchas y variadas experiencias de enseñanza.

- Abordar la formación como «experiencia» que habilite a experimentar.

Exploraremos en lo que sigue algunas formas especificas o apropiadas para la transmisión del saberhacer (todo junto) que se distinguen de las formas dominantes para la transmisión del conocimiento formalizado. Ahora bien, al tratarse de un saber tan personal y poco codificado ¿puede transmitirse a otros?, ¿de qué modo? Mientras la experiencia en sí misma es personal, subjetiva e intransferible, los saberes de oficio que de ella se derivan, sí pueden ser transmitidos. La respuesta a la inquietud por el «cómo» formar 
en un oficio podemos encontrarla en la recuperación de lo que sucede en el taller del artesano, donde se trata de reconstruir «los mil pequeños movimientos cotidianos que se agregan a una práctica» ${ }^{47} \mathrm{y}$ en lo que hacen los formadores de adultos: "dicho trabajo parece construido en torno a un centro, el oficio: el oficio a transmitir y el oficio de transmisión». ${ }^{48}$

¿Qué ocurría en los talleres y en los gremios de antaño cuando se enseñaba un oficio?

Llegar a saber hacer algo bien lleva tiempo:

- En los gremios medievales la duración del aprendizaje era de 7 años y tomaba hasta 10 la presentación de una «obra maestra», por la que el aprendiz debía convencer a sus maestros de que podía llegar a ser uno de ellos.

- Cuanto más lenta y exploratoria era la práctica del oficio más fiable parecía. Los resultados inmediatos eran sospechosos.

- Había etapas de progreso en el aprendizaje: al comienzo la presentación del aprendiz se basaba en la imitación del procedimiento, luego en la producción de una obra propia en la que el oficial debía demostrar competencia de gestión y liderazgo.

- Esa lentitud posibilita la reflexión y la imaginación al tiempo que permite disfrutar durante su adquisición. Las habilidades así adquiridas son duraderas.

¿Qué hacían los MAESTROS que formaban en gremios y talleres para que se adquieran habilidades?

- El maestro basa su autoridad en la transferencia de habilidades.

- Brinda instrucciones personales y prácticas.

- Transfiere los «secretos» de oficio, aquellos que fueron construyendo personalmente durante su práctica.

- Se ocupa en persona de los detalles más insignificantes de la producción.

\footnotetext{
47 Sennett, El artesano, 101.

48 Dubet, El declive de la institución, 194.
} 
- La formación técnica implica el contacto directo con los instrumentos $y$ explicaciones orales.

- Asume el compromiso de lograr que todos puedan hacerlo y confía en que todos podrán hacerlo.

- El taller bien administrado debía equilibrar el conocimiento tácito (el que sostiene la acción, eso que por lo general no se cuenta) y el explícito.

- El orfebre comprobaba la teoría con sus manos.

Es importante que los maestros logren explicar, sacar a la luz el conjunto de pistas y movimientos que habian asimilado silenciosamente en su interior. Gran parte de su autoridad viene de ver lo que otros no ven, de saber lo que otros no saben. ${ }^{49}$

- Los miembros de los gremios forjaban un fuerte sentimiento de comunidad.

- Los rituales del trabajo aseguraban la cohesión social.

¿Qué hacen los que forman adultos en un oficio?

- En primer lugar, los formadores son tales porque saben de su oficio. Si bien no se muestran como «modelos acabados», como sabiéndolo todo, saben de qué se trata lo que tienen que enseñar. Aún así, están en proceso de formarse y, de hecho, continúan haciéndolo mientras enseñan a otros.

- Los que forman a otros ayudan, acompañan y también enseñan, no sólo las competencias técnicas sino también las competencias sociales y capacidades de "adaptación» a los escenarios laborales diversos y cambiantes.

- Además de saber hacerlo, a los formadores les gusta lo que hacen, y pueden mostrarlo y ofrecerlo porque están orgullosos de ello. El oficio los define y están dispuestos a dar lo máximo de sí, con la esperanza de que lo suyo sirva de base para el despegue de los otros.

- Finalmente y pese a que las condiciones no siempre resultan del todo favorables, el discurso de los formadores es excepcionalmente estable

49 Sennett, El artesano, 102. 
y apacible, sereno y poco vacilante. Porque están convencidos de que tienen algo valioso que dar, que legar, que dejar en otros, más allá de espacios, tiempos, condiciones sociales y situaciones adversas.

Es en este encuentro entre el experimentado y el novato donde se crea el espacio para la transmisión de un oficio: mostrando lo que se hace, acompañando y ayudando, y también en la explicitación de lo que se hace, favoreciendo la experimentación, el tanteo, la prueba y la producción por parte de quienes se están formando. Transmitiendo además, orgullo, pasión y compromiso por y con lo que se hace. En este proceso, el novato va incorporándose en una comunidad sostenida en un oficio.

¿Cuán próximos o alejados de estas «formas de formar» estamos en las instancias de formación docente? Daremos un paso más en nuestra exploración y avanzaremos considerando lo que es posible aprender de la experiencia: de la propia y también de la de otros.

\section{APRENDER DE LA PROPIA EXPERIENCIA}

El aprender haciendo es fundamental para la adquisición de cualquier habilidad. El docente aprenderá a enseñar enseñando o, mejor, inserto en el proceso en el que se produce la enseñanza, ya sea en escenarios reales o en condiciones especialmente creadas en los distintos espacios de la formación. Ahora bien, no se trata de puro hacer o de hacer sin más, se trata de aprender a enseñar en este proceso.

Combinar la repetición y la imaginación. La repetición es una cualidad esencial de este tipo de aprendizaje. Al repetir una práctica podemos ir poco a poco modificándola, cambiándola o mejorándola. Sin embargo, de la propia práctica se obtiene saber siempre que se desarrolle más centrada en la imaginación que en la mecánica de la acción. Para aprender de lo que hacemos es importante concebir que ese hacer es un inter-juego constante entre solución y apertura de nuevos problemas, entre ejecución y creación. Es una dinámica similar a la que se da en la práctica del juego. Al jugar los niños repiten (y hasta disfrutan al hacerlo) determinadas acciones pero en esas mismas repeticiones van innovando, van inventando, van creando. Una extraña síntesis entre repetición e imaginación; tenacidad e ingeniosidad.

La reiteración de escenas y situaciones cobra sentido en la medida que sean concebidas en su singularidad, en su especificidad, lo que dará lugar a 
la exploración, a la indagación y a la experimentación de cursos de acción alternativos en una dinámica formativa que implica instancias de inmersión y de distanciamiento. Para el caso de la docencia, las circunstancias vividas las constituyen tanto las prácticas reales o simuladas que quienes se están formando puedan realizar durante su formación, como aquellas que protagonizaron siendo alumnos a lo largo de su recorrido escolar previo. ${ }^{50}$ Ahora bien, no se trata de «hacer» sin más; es preciso hablar, escribir, pensar narrar y producir saber a partir de lo hecho o vivido en determinadas circunstancias. En este momento «distanciado» de lo que se hizo o se vivió, se trata de problematizar las evidencias y aprender de todo aquello que acontece por fuera de lo esperado, de la norma, de lo naturalizado porque es precisamente eso lo que prepara para afrontar la complejidad propia de las situaciones escolares actuales. Más que luchar contra lo problemático, tendríamos que poder aprovechar el aprendizaje que este tipo de situaciones proporcionan. Lo imperfecto, lo fuera del modelo, de lo frecuente, de lo esperado, de lo conocido se convierten entonces en experiencias que instruyen a quienes se están formando. En términos de Edelstein, es preciso lograr una «reconstrucción crítica de la experiencia» y así lo expresa:

Postulamos la reconstrucción crítica como invitación a un ejercicio sistemático de producción de un efecto de extrañeza y desfamiliarización que ponga en suspenso las evidencias, las categorías y modos habituales de pensar, de describir y explicar, en este caso, las prácticas de enseñanza. Procurar pensarlas de otro modo; admitir las vías de entrada más diversas para una lectura, una mirada, una escucha $\mathrm{y}$, de esa manera, reconstruir su compleja trama. ${ }^{51}$

\section{APRENDER DE LA EXPERIENCIA DE OTROS}

No sólo se aprende lo que uno hace, hizo o vivió, sino que en estos procesos resulta altamente formativo aquello que otros hacen o hicieron. De nuevo, el potencial instructivo de estas experiencias depende de las condiciones en que se desarrollen.

\footnotetext{
${ }^{50}$ A diferencia de otras profesiones, la docencia acontece en una institución escolar que se ha frecuentado durante muchos años y en etapas decisivas de la vida siendo alumno. Distintos trabajos reconocen el poder formativo que esta experiencia vivida en la escolaridad tiene para el ejercicio profesional. Ver, por ejemplo, Andrea Alliaud, La biografía escolar en el desempeño profesional de los docentes noveles. Tesis de Doctorado (Universidad de Buenos Aires: Facultad de Filosofía y Letras, 2004).

${ }^{51}$ Gloria Edelstein, Formar y formarse en la enseñanza (Buenos Aires: Paidós, 2011), 140.
} 
Mostrar antes que explicar. En formación docente, como en cualquier otro oficio, la práctica de los formadores tiene un poder formativo mucho mayor que los discursos: lo que decimos o predicamos acerca de ella. Tenemos que ser conscientes que la manera en que enseñamos a los docentes en formación, enseña más que lo que decimos o predicamos acerca de la enseñanza. ¿Cómo enseñamos a los futuros docentes? ¿Qué les mostramos? ¿Qué les ofrecemos? ¿Qué experiencias generamos en ellos como estudiantes/alumnos/ futuros docentes?

Además de la práctica del formador, y con el aditivo que conlleva porque se experimenta desde el lugar de estudiante/ alumno, también es formativa la obra de otros docentes. Quienes se están formando para enseñar aprenden de las enseñanzas que les brindan sus formadores y también de las que tengan oportunidad de frecuentar: las de otros docentes que trabajen o hayan trabajado en las aulas con alumnos a partir de lo cual tengan algo para contar, un saber que consideran valioso para legar; las que presencian en vivo y en directo y también las que decidamos mostrarles en otros soportes tales como filmaciones, relatos u obras de enseñanza ¿A quiénes invitamos? ¿Qué enseñanzas será posible obtener de aquellas experiencias que suceden?

Así como resulta un componente fundamental de la formación artística, el contacto y la familiarización con «buenas» obras de arte que en general resultan ser producciones de «grandes» maestros, lo mismo podría pensarse para la formación docente. Se trata en este caso de rescatar el potencial formador que tienen las obras de otros para aprender a hacer la propia obra. ¿Hay buenas obras de enseñanza, las podemos detectar? ¿Existen los «grandes» en este campo? Vale la pena buscarlos, identificarlos y usarlos. Más aquí o más allá y en diferentes momentos históricos. Porque lo que importa no es tanto el contexto como el saber (de la experiencia) que se transmite, por su potencial inspirador, provocador y hasta desafiante, para el emprendimiento de la propia producción, de la propia creación. En el sentido que lo expresara Orhan Pamuk en El placer de pintar: "Dibujaba recordando aquellas imágenes pero los dibujos eran míos».52

En ambos casos se advierte la impronta formativa que este tipo de experiencias representa para los docentes, siempre que se evite caer en la concep-

52 Orhan Pamuk, Estambul. Ciudad y recuerdos (Barcelona: Mondadori, 2006), 174. 
ción modélica originaria,53 propia de los procesos educativos que acontecen dentro del sistema escolar. La familiarización con las enseñanzas de otros no tiene por finalidad que quienes se están formando aspiren a hacer lo mismo que hace o hizo «el modelo», a replicarlo para llegar a parecerse a él. Por el contrario, las enseñanzas de los otros «sirven» si ayudan a enseñar, si se presentan y conciben como una posibilidad, como una referencia que inspira la creación de la obra propia, de la propia enseñanza. Si nos dejan mejor provistos para hacerlo, si aportan herramientas para solucionar un problema que se presenta en lo que se está haciendo; si despiertan el deseo de enseñar:

[...] uno puede aprender de lo que otros hacen, dicen, hicieron, dijeron o produjeron sin quedarse en la antesala, en el homenaje o en la admiración del grande, del modelo acabado, del que le salió bien y fue reconocido por ello. Uno puede aprender utilizando el leguaje de otro, tomando ideas o palabras prestadas, siempre que reconozca la propia potencia en su hacer, su propia creación, su propia sensibilidad, su propia producción. Sólo desde esta concepción, resulta más que interesante aprender imitando, creando a partir de lo hecho por otros. ${ }^{54}$

Las enseñanzas que ofrecemos y las que elegimos mostrar, ¿aportan enseñanzas a quienes se están formando?, ¿brindan herramientas o insumos para emprender la propia enseñanza?, ¿despiertan el deseo de enseñar?

La pasión y el compromiso con lo que se hace, además de los saberes más específicos, se convierten asimismo en contenidos relevantes en los procesos de transmisión del oficio. En el caso de la docencia, ese «plus» del oficio antes estaba dado por la vocación entendida como una adhesión sacrificada hacia valores universales. Hoy, esa cualidad valorativa que se suma a la dimensión instrumental de la tarea y que es ineludible, por ser propia de todas aquellas profesiones que «trabajan sobre otros», descansa en el compromiso. Desde esta acepción más acorde con los tiempos que corren, saber y poder enseñar y hacerlo «bien» tiene un valor cuyo alcance no sólo llega a cada sujeto individual sino que compete a todos. Tenemos entre manos un oficio que nos conecta con la posibilidad de formación/ transformación de las personas, con la transmisión de la cultura a las nuevas generaciones. El

\footnotetext{
${ }^{53}$ La vigencia de los modelos en el sistema escolar y particularmente en la práctica y formación de los docentes, ha sido desarrollada en profundidad en otro trabajo. Ver Andrea Alliaud, «La maestra modelo y el modelo de maestra», en Los gajes del oficio. Enseñanza, pedagogía y formación, eds. Andrea Alliaud y Estanislao Antelo (Buenos Aires: Aique, 2009), 65-79.

${ }^{54}$ Alliaud, «La maestra modelo», 72-73.
} 
compromiso no es entonces ni con el más acá (con los sujetos con los que se trabaja ni con uno mismo porque le gusta lo que está haciendo) ni con el más allá, como era concebida la vocación de antaño. Es, más bien, con lo que somos y con lo que hacemos porque elegimos hacerlo: el pasaje del acervo cultural a las nuevas generaciones. Más que el amor a los niños, es la pasión con la transmisión y con aquello que se está transmitiendo.

Hablar de lo que se hizo. El hacerlo sin más, forma, enseña, pero la descripción o demostración de lo que se está haciendo, la puesta en palabras, enriquece el proceso de aprendizaje del que se está formando. Estamos convocando una modalidad típica del aprendizaje llevado a cabo en los antiguos gremios y talleres y hasta de los laboratorios modernos, donde maestros y aprendices trabajan juntos aunque no como iguales. El que está aprendiendo mira/observa cómo el otro lo hace mientras el maestro va describiendo lo que hace y de este modo su exposición se convierte en guía.

Cuando el oficio es la enseñanza, se trata de que el docente o maestro que estuvo a cargo de una clase pueda hablar de ella: hablar de lo que hizo y cómo lo hizo. También puede ser ésta una posibilidad para los formadores. En ambos casos y nuevamente depende de qué se cuente y cómo se cuente. Suele no resultar dar órdenes o utilizar verbos imperativos (hacer, decir, poner, sacar) que indiquen al otro/a lo que tiene que hacer. Más fructífero aunque no tan sencillo es revelar el conocimiento tácito que sostiene las acciones desarrolladas, aquello de lo que en general no se habla. En el caso de las clases, sería poner en palabras el procedimiento de lo que se hizo y su justificación: «en el momento que saqué los materiales lo hice porque me di cuenta de que los alumnos no estaban entendiendo»; «decidí acortar el tiempo de la explicación cuando percibí que el tiempo disponible no era suficiente»; «aproveché la pregunta de Juan para iniciar una síntesis del tipo de las que uno ve en los noticieros, para dar un par de ejemplos».

El desafío en este caso es develar aquello que para el «experto» (el que lo sabe hacer) constituye lo habitual, lo evidente, lo natural. Las obviedades de unos serán conocimiento valioso para quienes se está formando. A la hora de hablar del propio trabajo, puede resultar valerse de: analogías apelando a situaciones conocidas para el que está aprendiendo (comparar las acciones implicadas en la enseñanza con situaciones cotidianas) sabiendo que el acudir a lo que a lo que uno ya ha hecho y conoce, otorga seguridad y confianza; metáforas que promuevan la comprensión y la imaginación (las metáforas 
permiten acceder más fácilmente a los procedimientos implícitos en cada una de las acciones que entran en juego en el hacer/obrar); y color adverbial, haciendo referencia a las tonalidades y matices propias de los acciones en determinadas situaciones.

Asimismo a la hora de hablar sobre la enseñanza se aconseja utilizar ejemplos, hechos vividos, anécdotas que vengan al caso para ilustrar y dar fuerza a lo que se está contando. También apelar a figuras propias de otros campos. ¿Por qué no la literatura o el cine que, mediante imágenes e historias de distintos tiempos y espacios, permiten acceder a otros mundos y enriquecer el abanico de posibilidades? Conviene tener a mano un repertorio de escenas de enseñanza. A través de estas "herramientas imaginativas ${ }^{55}$ los conocimientos implícitos se convierten en guías prácticas, orientadoras del hacer de quienes se están formando. Este tipo de relato conecta el oficio técnico con la imaginación; orienta acerca del sentido de totalidad de una práctica facilitando así la comprensión del proceso.

Finalmente, es importante que quienes están enseñando a enseñar y hablen acerca de su enseñanza, transmitan no sólo en los procedimientos técnicos sino también los "secretos», los misterios o los "gajes» del oficio. Al igual que la cocina, la enseñanza tiene sus trucos y estos se van descubriendo, construyendo y validando en la propia práctica, siendo sus portadores los docentes que han enseñado. Son estas raras fórmulas o mezclas de métodos, técnicas y modos de actuar que se ponen a prueba y se van modificando en función de lo que sucede en situaciones concretas, poderosas herramientas para poder hacerlo. De ellos no dan cuenta ni los tratados de pedagogía ni los de didáctica, son los que enseñaron mucho los que pueden ofrecerlos a quienes se están formando. Una cosa es decir «condimentar la carne» y otra hacer referencia al momento oportuno y a la forma de hacerlo o aludir a condimentos posibles según la disponibilidad. ¿Cómo sería para la enseñanza?

\section{APRENDER JUNTOS}

Ante situaciones complejas e inciertas, cuando ya los profesores comprenden que no pueden superar por sí solos los desafíos que la tarea les presenta, el trabajo colectivo se vuelve no sólo un recurso sino una necesidad para «recuperar la seguridad, para no considerar a los fracasos como

55 Sennett, El artesano, 261-262. 
resultantes únicamente de su responsabilidad personal y para renovar su motivación al abordar experiencias pedagógicas». ${ }^{56}$ Desde esta perspectiva para favorecer la enseñanza, habría que "socializar los problemas de oficio», ${ }^{57}$ tratando de asumir colectivamente la responsabilidad por la producción que ya no será de cada individuo, sino de todos los que trabajan juntos. En este sentido, mejorar la «productividad», la calidad de lo que se hace, y mejorar las maneras de hacerlo se une a formas colectivas e institucionalizadas de ejercer el oficio de enseñar.

Para Sennett, ${ }^{58}$ el trabajo colectivo motiva a hacer las cosas bien y $\mathrm{fa}$ vorece la producción de una artesanía o un trabajo de buena calidad. Por el contrario, cuando desaparece la cooperación y predominan los solistas y la competencia entre ellos, el trabajo se degrada. A diferencia de lo que ha afirmado el capitalismo occidental, no es la competencia, sino la colaboración lo que motiva a las personas en su trabajo.

Ahora bien, la gente necesita practicar las relaciones interpersonales implicadas en el trabajo con otros. De allí la relevancia de propiciar en los ámbitos de formación docente relaciones colaborativas entre los formadores y quienes están protagonizando procesos de formación. Uno se forma y aprende a trabajar con otros en la medida que produce sintiéndose protagonista y relevante en un proyecto que compete a todos. Tanto las habilidades propias como las diferencias, son valiosas en aquello que se produce. Aprender a solucionar y descubrir problemas, a pensar y a reflexionar con otros, fortalece el oficio y, por lo tanto, contribuye a mejorar aquello que se produce.

$\mathrm{Al}$ estar incrustada en una gramática escolar dividida y fragmentada, desde sus orígenes las prácticas educativas/formativas institucionalizas fueron concebidas desde la esfera individual y referenciadas en las paredes de un aula o en una porción de conocimiento. Conviene en este caso recordar que «las capacidades de la gente para cooperar son mucho mayores y más complejas de lo que las instituciones permiten». ${ }^{59}$ Aprovechémoslas.

\footnotetext{
56 Dubet, El declive de la institución, 183.

${ }^{57}$ Danilo Martuccelli, «La autoridad en las salas de clase. Problemas estructurales y márgenes de acción», Diversia, CIDPA. Valparaíso, 1 (2013): 107.

${ }^{58}$ Sennett, El artesano, 46, y Juntos. Rituales, placeres y política de cooperación (Barcelona: Anagrama, 2012), 22-23.

${ }^{59}$ Sennet, Juntos, 52.
} 


\section{CONCLUSIONES}

Como he sostenido en otros trabajos, hoy enseñar es difícil para todos y en todas las escuelas. En el primer o tercer mundo. Maestros y profesores más o menos formados, con mayor o menor experiencia, con más o menos saber, con mucha o poca paciencia. Escuelas estatales, privadas, pobres, ricas, medias, urbanas, rurales, grandes o chicas. Hoy a todos nos cuesta en todos lados. Muchos y complejos resultan los análisis producidos que tratan de dar cuenta de esta dificultad. Por eso, en este escrito he pretendido avanzar en el esbozo de una propuesta de formación docente basada en las formas de transmisión de un oficio, desde una visión superadora de las lógicas originarias de la docencia y su formación aunque re-significando algunos de sus componentes.

Ello no significa simplificar el problema, sino atenderlo en su especificidad. La escuela de hoy si bien conserva su formato o gramática original, se diferencia de la de antaño. El «trabajo sobre los otros» ya no puede realizarse a partir de fórmulas estandarizadas ni de conocimientos mínimos. Hoy para poder educar/intervenir/transformar y lograr que quienes están en la escuela aprendan — porque de eso sigue tratándose la enseñanza-, no parece resultar actuar a gran escala, ofreciendo a todos lo mismo y por igual. Por el contario, el trabajo de enseñar se va construyendo "artesanalmente» en el día a día, paso a paso. En tiempos en que la enseñanza se complejiza, si bien es necesario sumar a la formación nuevos conocimientos formales y dotarlos de mayor complejidad y profundidad, también se requiere poner en valor, recuperar e incluir a aquellos saberes (de la experiencia) que aluden a lo particular, a la producción, a la creación y a la experticia en lo que se hace. Representa ésta una vía potencialmente inclusiva: creando las condiciones propicias es posible que todos logren ser «artesanos» en lo que hacen (artesanos de la enseñanza) o lo que es lo mismo, hacer las cosas bien. Además de traer beneficio para quienes enseñan, esta opción resulta provechosa para todos. 


\section{Nota sobre los autores:}

Andrea Alliaud es Doctora en Educación por la Universidad de Buenos Aires. Actualmente se desempeña como Profesora Adjunta del Departamento de Ciencias de la Educación de la Facultad de Filosofía y Letras de la Universidad de Buenos Aires (UBA), institución en la que también dirige Programas de Investigación (UBACYT) destinados al estudio del saber de la experiencia de los docentes. Es además profesora de posgrado en la Carrera de Especialización y Maestría en Administración de la Educación y Política Educativa de la Universidad Torcuato Di Tella. Su área de especialización, desde hace más de veinte años, es la formación de profesores, temática sobre la que investigó, disertó y publicó tanto en el país como en el exterior. Entre sus libros se destacan: Los maestros y su historia. Los orígenes del magisterio argentino; Los gajes del oficio. Enseñanza, pedagogía y formación; El saber de la experiencia. Narrativa. Investigación y formación docente. Se desempeñó como consultora en organismos nacionales e internacionales tales como el Ministerio de Educación de la Nación y la Organización de Estados Iberoamericanos. Entre los años 2006 y 2007 fue Directora General de Educación Superior en el Ministerio de Educación del Gobierno de la Ciudad Autónoma de Buenos Aires. 